\title{
Aspectos epidemiológicos, clínicos e assistenciais da monitorização hemodinâmica invasiva: uma revisão bibliográfica
}

\author{
Epidemiological, clinical and assistence aspects of invasive \\ hemodynamic monitoring: a bibliographic review
Aspectos epidemiológicos, clínicos y de cuidado de la monitorización hemodinámica invasiva: una revisión bibliográfica \\ Patrick Leonardo Nogueira da SILVA ${ }^{(1)}$ \\ Amanda Gesiele Pereira SANTOS ${ }^{(2)}$ \\ Bianca Gonçalves RODRIGUES ${ }^{(2)}$ \\ Bruna Rodrigues NOVI ${ }^{(2)}$ \\ Daniele Zuba RAMOS ${ }^{(2)}$ \\ Pollyane Teixeira ROCHA ${ }^{(2)}$ \\ Priscila Karolline Rodrigues CRUZ ${ }^{(2)}$ \\ Luciana Barbosa PEREIRA ${ }^{(2)}$
}

Recebido: 20 out 2016 Revisado: 19 fev 2017 Aceito: 10 maio 2017

\section{Autor de}

correspondência:

Patrick Leonardo

Nogueira da Silva

patrick_mocesp70@hotmail.com

Conflito de interesses:

Os autores declaram não

haver nenhum interesse profissional ou pessoal que possa gerar conflito de interesses em relação a este manuscrito.

\footnotetext{
${ }^{(1)}$ Fundação Hospitalar do Município de Espinosa - FHUMESP, Espinosa, MG, Brasil.

(2) Universidade Estadual de Montes Claros - UNIMONTES, Montes Claros, MG, Brasil.
}

\begin{abstract}
Resumo
A monitorização hemodinâmica refere-se à monitorização invasiva do sistema arteriovenoso, utilizado para medir pressões intracardíacas, intrapulmonares, intravasculares e também para determinar a eficácia da terapia. Este estudo objetivou identificar os aspectos epidemiológicos, clínicos e assistenciais da monitorização invasiva, bem como seus tipos. Trata-se de um estudo descritivo, documental e de revisão bibliográfica. A amostra foi composta por 18 artigos compreendidos entre 1984 a 2016 na qual abordava a temática. A coleta dos dados foi realizada durante o $2^{\circ}$ semestre de 2016 por meio de um formulário. Verificou-se que sete artigos tratavam de revisão de literatura; dez, de pesquisa de campo e um estudo de caso. O número de autores por artigo variou entre um a seis. Dos objetivos propostos, identificou-se que a maioria abordava a utilização dos vários métodos de monitorização invasiva, avaliação da técnica utilizada pela equipe de saúde, relatar conceitos e enfatizar as medidas de biossegurança na enfermagem. Constatou-se que o número de pacientes graves em estado crítico tem aumentado consideravelmente por múltiplas causas de modo que, tanto a demanda nas Unidades de Tratamento Intensivo, quanto o uso da monitorização hemodinâmica invasiva neste setor, tem se tornado de fundamental importância para o tratamento e recuperação do paciente. O conhecimento acerca da monitorização hemodinâmica invasiva ajuda a desenvolver a capacidade de decisão clínica, passando do simples registro dos sinais vitais para a interpretação e análise daquela informação, de modo a formular um plano de cuidados de enfermagem apropriado para aquele indivíduo.
\end{abstract}

Descritores: Monitoramento; Pressão Intracraniana; Pressão Venosa Central; Enfermagem. 


\begin{abstract}
Hemodynamic monitoring refers to invasive monitoring of the arteriovenous system, used to measure intracardiac, intrapulmonary, intravascular pressures and also to determine the efficacy of the therapy. This study aimed to identify the epidemiological, clinical and assistance aspects of invasive monitoring, as well as its types. This is a descriptive, documental and bibliographic review study. The sample consisted of 18 articles from 1984 to 2016 in which the subject was discussed. Data collection was performed during the second half of 2016 by means of a form. It was verified that seven articles dealt with literature review; Ten, field research and a case study. The number of authors per article ranged from one to six. From the proposed objectives, it was identified that the majority addressed the use of the various methods of invasive monitoring, evaluation of the technique used by the health team, reporting concepts and emphasizing biosafety measures in nursing. It was found that the number of critically ill patients has increased considerably by multiple causes so that both the demand in the Intensive Care Units and the use of invasive hemodynamic monitoring in this sector has become of fundamental importance for the treatment And patient recovery. Knowledge about invasive hemodynamic monitoring helps to develop clinical decisionmaking capacity, from simple vital signs recording to interpretation and analysis of that information, in order to formulate an appropriate nursing care plan for that individual.
\end{abstract}

Keywords: Monitoring; Intracranial Pressure; Central Venous Pressure; Nursing.

\title{
Resumen
}

La monitorización hemodinámica se refiere a la vigilancia de sistema arteriovenosa invasivo utilizado para medir la presión intracardiaca, intrapulmonar, intravascular y también para determinar la efectividad del tratamiento. Este estudio tuvo como objetivo identificar los aspectos epidemiológicos, clínicos y cuidar los aspectos de la monitorización invasiva, así como sus tipos. Se trata de un estudio descriptivo, de documentos y revisión de la literatura. La muestra consistió en 18 artículos que van desde 1984 hasta 2016 en el que abordó el tema. La recolección de datos se llevó a cabo durante la segunda mitad de 2016 a través de un formulario. Se encontró que siete artículos tratados revisión de la literatura; diez investigación de campo y un estudio de caso. El número de autores por artículo variaba entre uno y seis. Los objetivos propuestos, se identificó que la mayoría se referían a la utilización de diversos métodos de monitorización invasiva, la evaluación de la técnica utilizada por el equipo de salud, registro de conceptos y hacer hincapié en las medidas de bioseguridad en enfermería. Se encontró que el número de pacientes críticamente enfermos en estado crítico ha aumentado considerablemente por múltiples causas de modo que tanto la demanda de unidades de cuidados intensivos, y el uso de la monitorización hemodinámica invasiva en este sector, se ha vuelto crucial para el tratamiento y la recuperación del paciente. El conocimiento de la monitorización hemodinámica invasiva ayuda a desarrollar la capacidad de toma de decisiones clínicas, a través del simple registro de signos vitales para la interpretación y el análisis de esa información con el fin de formular un plan de atención de enfermería adecuada para ese individuo.

Palabras-claves: Monitoreo; Presión Intracraneal; Presión Venosa Central; Enfermería.

\section{Introdução}

A monitorização hemodinâmica refere-se à monitorização invasiva do sistema arterial e venoso, utilizada para medir pressões intracardíacas, intrapulmonares, intravasculares e também para determinar a eficácia da terapia. ${ }^{1}$ Apesar do rápido avanço 
das técnicas de monitorização não invasiva, a monitorização hemodinâmica invasiva é fundamental nas Unidades de Terapia Intensiva - UTI. ${ }^{1,2}$ A avaliação do doente crítico fazse por meio da utilização do monitor cardíaco, das linhas de monitorização hemodinâmica e das análises laboratoriais, o que difere na sua avaliação de outros doentes. Porém, os dados da monitorização não significam nada se não forem somados a achados físicos e analisados de forma crítica pelo enfermeiro. ${ }^{3}$

O profissional deve ser capaz de selecionar e executar o método de monitorização mais apropriado de acordo com as necessidades individuais do paciente, considerando a relação risco-benefício da técnica. Esta monitorização é feita por meio da utilização de cateteres e transdutores que ligados ao sistema, mostram os resultados encontrados em forma de onda no monitor cardíaco. ${ }^{2}$

O paciente crítico com monitorização invasiva fica exposto a riscos adicionais que são as complicações, tal como a embolia gasosa, a hemorragia, a má colocação dos cateteres, a lesão dos tecidos ou comprometimento hemodinâmico decorrente da introdução de um corpo estranho ou do seu posicionamento incorreto. Desta forma, é fundamental que o enfermeiro utilize técnica asséptica para manutenção dos sistemas e avalie de forma contínua a resposta do doente ao equipamento; pesquise sinais inflamatórios nos locais de inserção dos cateteres; crie uma rotina de substituição dos pensos. $^{3}$

A monitorização de funções vitais é uma das mais importantes e essenciais ferramentas no manuseio de pacientes críticos na UTI. Hoje é possível detectar e analisar uma grande variedade de sinais fisiológicos através de diferentes técnicas, invasivas e não invasivas. O intensivista deve ser capaz de selecionar e executar o método de monitorização mais apropriado de acordo com as necessidades individuais do paciente, considerando a relação risco-benefício da técnica. Apesar do rápido desenvolvimento de técnicas de monitorização não invasiva, a monitorização hemodinâmica invasiva com o uso do cateter de artéria pulmonar (CAP) ainda é um dos procedimentos fundamentais em UTI. 
Sendo assim, este estudo objetivou identificar os aspectos epidemiológicos, clínicos e assistenciais da monitorização invasiva, bem como seus tipos, por meio da literatura científica.

\section{Metodologia}

Trata-se de um estudo descritivo, documental e de revisão bibliográfica, realizado através das seguintes etapas: coleta de dados, avaliação dos dados, análise e interpretação dos dados coletados e apresentação dos resultados, na qual este método tem a finalidade de reunir e sistematizar resultados de pesquisas sobre um delimitado tema ou questão de maneira sistemática e ordenada, contribuindo para o aprofundamento do conhecimento do tema investigado.

A coleta de dados ocorreu no $2^{\circ}$ semestre de 2016. Foram acessados artigos publicados no período de 1984 a 2016, indexados nas bases de dados da Biblioteca Virtual da Saúde - BVS, sendo estas: Scientific Eletronic Library Online (SciELO), Literatura Internacional em Ciências da Saúde - MEDLINE, Literatura Latino-Americana e do Caribe em Ciências da Saúde - LILACS e a Base de Dados da Enfermagem - BDEnf. Utilizaram-se os seguintes descritores de saúde: "Monitoramento", "Pressão Intracraniana", "Pressão Venosa Central", "Enfermagem".

Foram adotados os seguintes critérios de inclusão para a captação dos dados: artigos completos, nacionais e internacionais, disponível gratuitamente; publicado nos últimos 32 anos (1984-2016); e que contemplasse a temática. O processo de análise dos dados ocorreu através da análise textual, que de acordo com aprofundamento em processos discursivos, visou proporcionar subsídios para o conhecimento crítico e aprofundado do assunto optado. Os dados estatísticos foram expressos em tabelas construídas por meio do programa Microsoft Exce/®, versão 2010, apresentando frequências absolutas e percentuais.

Obteve-se como resultado 169 publicações (Tabela 1). A partir do enfoque na 
temática, foi realizada a leitura preliminar dos resumos desses artigos e, posteriormente à leitura, foi estabelecida uma seleção dos artigos na qual satisfizeram os critérios de inclusão, resultando em 18 publicações para análise. A exclusão de 151 artigos se deu em decorrência ao não cumprimento dos critérios de inclusão estabelecidos (Tabela 2). Após a definição da amostra, realizou-se a leitura aprofundada dos artigos selecionados para posterior discussão dos mesmos.

Tabela 1. Perfil amostral da coleta de dados quanto à sua distribuição nas bases de dados online em relação aos descritores utilizados.

\begin{tabular}{|c|c|c|c|c|c|c|c|c|c|}
\hline Base de dados & & & & MEI & & & & & \\
\hline Descritores & & $\mathbf{n}$ & $\%$ & $\mathbf{n}$ & $\%$ & $\mathbf{n}$ & $\%$ & $\mathbf{n}$ & $\%$ \\
\hline $\begin{array}{l}\text { Monitoramento AND } \\
\text { Intracraniana AND P } \\
\text { Venosa Central }\end{array}$ & $\begin{array}{l}\text { Pressão } \\
\text { Pressão }\end{array}$ & 0 & 0 & 19 & 11,5 & 0 & 0 & 0 & 0 \\
\hline $\begin{array}{l}\text { Monitoramento AND P } \\
\text { Intracraniana } \\
\text { Enfermagem }\end{array}$ & $\begin{array}{r}\text { Pressão } \\
\text { AND }\end{array}$ & 0 & 0 & 109 & 66,4 & 3 & 100 & 2 & 100 \\
\hline $\begin{array}{l}\text { Monitoramento AND P } \\
\text { Venosa Central } \\
\text { Enfermagem }\end{array}$ & $\begin{array}{r}\text { Pressão } \\
\text { AND }\end{array}$ & 0 & 0 & 35 & 21,3 & 0 & 0 & 0 & 0 \\
\hline $\begin{array}{l}\text { Pressão Intracraniana } \\
\text { Pressão Venosa Central } \\
\text { Enfermagem }\end{array}$ & $\begin{array}{ll} & \text { AND } \\
\text { al } & \text { AND }\end{array}$ & 0 & 0 & 1 & 0,8 & 0 & 0 & 0 & 0 \\
\hline TOTAL & & 0 & 0 & 164 & 100 & 3 & 100 & 2 & 100 \\
\hline
\end{tabular}

Fonte: Elaborado pelos autores (2016).

Tabela 2. Perfil da amostra selecionada conforme os critérios de inclusão e exclusão.

$\begin{array}{lcccc}\text { Bases de dados } & \text { AS } & \text { AE } & \text { AU } & \text { Total } \\ \text { SciELO } & 0 & 0 & 0 & 0 \\ \text { MEDLINE } & 162 & 151 & 13 & 13 \\ \text { LILACS } & 3 & 0 & 3 & 3 \\ \text { BDEnf } & 2 & 0 & 2 & 2 \\ \text { Total } & \mathbf{1 6 9} & \mathbf{1 5 1} & \mathbf{1 8} & \mathbf{1 8}\end{array}$

Fonte: Elaborado pelos autores (2016).

Notas: $\mathrm{AS}=$ Artigo selecionado, $\mathrm{AE}=$ Artigo excluído, $\mathrm{AU}=$ Artigo utilizado 


\section{Resultados}

Sobre o trabalho e o tipo de publicação, verificou-se que sete tratavam-se de artigos de revisão; 10, de artigos de pesquisa (abordagem quantitativa e/ou qualitativa) e um estudo de caso. O número de autores por artigo variou entre um a seis, totalizando 75 articulistas. Quanto aos objetivos propostos pelas publicações, identificou- se que a maioria abordava a utilização dos vários métodos de monitorização invasiva, avaliação da técnica utilizada pela equipe de saúde, relatar conceitos e enfatizar as medidas de biossegurança na Enfermagem. Contudo, constatou-se pouca diversidade entre os objetivos a fim de subsidiar mais conhecimento técnico-científico acerca do tema (Tabela 3).

Tabela 3. Perfil do resumo da amostra encontrada conforme variáveis utilizadas para análise das publicações localizadas nas bases de dados online. ${ }^{1,2,4,5,6,7,8,9,10,11,12,13,14,15,16,17,18,19}$

\begin{tabular}{|c|c|c|c|c|c|c|c|}
\hline $\mathbf{N}^{\circ}$ & Título & Periódico & Ano & Método & Autor & Objetivo & Resultado \\
\hline 1 & $\begin{array}{l}\text { The } \\
\text { measurement } \\
\text { of intra- } \\
\text { abdominal } \\
\text { pressure as a } \\
\text { criterion for } \\
\text { abdominal re- } \\
\text { exploration }\end{array}$ & Ann Surg & 1984 & $\begin{array}{l}\text { Estudo de } \\
\text { caso }\end{array}$ & $\begin{array}{l}\text { Kron, } \\
\text { Harman, } \\
\text { Nolan }^{4}\end{array}$ & $\begin{array}{lr}\text { Estudar } & \text { um } \\
\text { grupo } & \text { de } \\
\text { pacientes } & \text { com } \\
\text { oligúria ou } \\
\text { anúria devido à } \\
\text { elevação da } \\
\text { pressão intra- } \\
\text { abdominal } \\
\text { (PIA). }\end{array}$ & $\begin{array}{l}\text { Sete pacientes } \\
\text { haviam marcado } \\
\text { elevação da PIA } \\
\text { e que todos } \\
\text { manifestaram } \\
\text { insuficiência } \\
\text { renal. Os quatro } \\
\text { pacientes que se } \\
\text { submeteram a } \\
\text { reexploração } \\
\text { abdominal e } \\
\text { evacuação de } \\
\text { sangue tiveram } \\
\text { uma diurese } \\
\text { rápida, embora } \\
\text { dois destes } \\
\text { pacientes depois } \\
\text { apresentassem } \\
\text { sepse. }\end{array}$ \\
\hline
\end{tabular}




\begin{tabular}{|c|c|c|c|c|c|c|c|}
\hline 2 & $\begin{array}{l}\text { A multicenter } \\
\text { study of } \\
\text { physician's } \\
\text { knowledge of } \\
\text { the pulmonary } \\
\text { artery } \\
\text { catheter. } \\
\text { Pulmonary } \\
\text { Artery } \\
\text { Catheter } \\
\text { Study Group }\end{array}$ & $\begin{array}{l}\text { JAMA - J Am } \\
\text { Med Assoc }\end{array}$ & 1990 & $\begin{array}{l}\text { Estudo } \\
\text { transversal, } \\
\text { de análise } \\
\text { quantitativa. }\end{array}$ & $\begin{array}{l}\text { Iberti, } \\
\text { Fischer, } \\
\text { Leibowitz, } \\
\text { Panacek, } \\
\text { Silverstein, } \\
\text { Albertson }^{5}\end{array}$ & $\begin{array}{lr}\text { Avaliar } & \text { o } \\
\text { conhecimento } \\
\text { dos r médicos } \\
\text { dos r } & \text { Estados } \\
\text { Unidos r r } & \text { e } \\
\text { Canadá e } & \text { a } \\
\text { compreensão } & \\
\text { do uso do CAP } \\
\text { e interpretação } \\
\text { dos r dados } \\
\text { obtidos. }\end{array}$ & 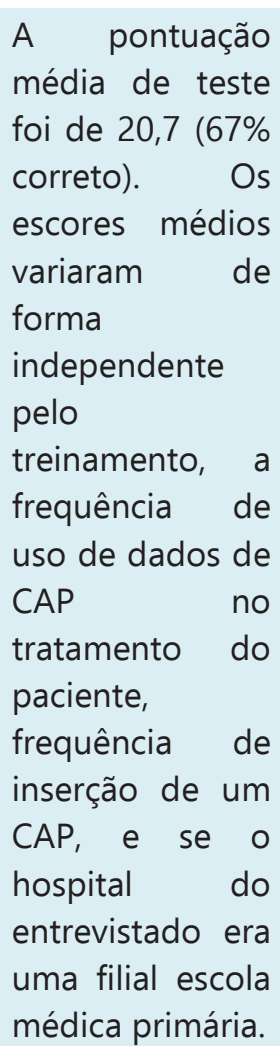 \\
\hline 3 & $\begin{array}{l}\text { Uso da } \\
\text { monitorização } \\
\text { hemodinâmic } \\
\text { a contínua } \\
\text { não invasiva } \\
\text { na } \\
\text { insuficiência } \\
\text { cardíaca } \\
\text { descompensa } \\
\text { da }\end{array}$ & $\begin{array}{ll}\text { Arq } & \text { Bras } \\
\text { Cardiol } & \end{array}$ & 2012 & $\begin{array}{l}\text { Estudo } \\
\text { comparativo, } \\
\text { com análise } \\
\text { quantitativa. }\end{array}$ & $\begin{array}{l}\text { Lima, } \\
\text { Ochiai, } \\
\text { Vieira, } \\
\text { Cardoso, } \\
\text { Brancalhão, } \\
\text { Puig, et al. }{ }^{6}\end{array}$ & $\begin{array}{l}\text { Comparar as } \\
\text { medidas } \\
\text { obtidas com a } \\
\text { monitorização } \\
\text { hemodinâmica } \\
\text { não invasiva } \\
\text { com as } \\
\text { invasivas em } \\
\text { pacientes com } \\
\text { insuficiência } \\
\text { cardíaca } \\
\text { descompensada } \\
\text { e refratária ao } \\
\text { tratamento. }\end{array}$ & $\begin{array}{l}\text { Foram realizadas } \\
56 \text { medidas em } \\
14 \text { pacientes } \\
\text { estudados em } \\
\text { dias e horários } \\
\text { diferentes } \\
\text { índice de } \\
\text { correlação entre } \\
\text { as medidas da } \\
\text { pressão arterial } \\
\text { sistólica (PAS) } \\
\text { foi de } r=0,26 \\
\text { (IC } 95 \%=0,00 \text { a } \\
0,49, p=0,0492) \\
\text { e da diastólica } \\
\text { de } r=0,50 \text { (IC } \\
95 \%=0,27 \text { a } \\
0,67, \quad p \\
0,0001) . \\
\text { correlação foi de } \\
r=0,55 \text { (IC } 95 \% \\
=0,34 \text { a } 0,71, p \\
0,0001) \text { para o } \\
\text { indice cardíaco e } \\
\text { de } r=0,32 \text { (IC } \\
95 \%=0,06 \text { a } \\
0,53, p=0,0178 \text { ) }\end{array}$ \\
\hline
\end{tabular}


ISSN 2179-6750

\begin{tabular}{|c|c|c|c|c|c|c|c|}
\hline & & & & & & & $\begin{array}{l}\text { para } \\
\text { resistência } \\
\text { vascular } \\
\text { sistêmica. }\end{array}$ \\
\hline 4 & $\begin{array}{l}\text { O cateter de } \\
\text { Swan-Ganz } \\
\text { deve ser } \\
\text { indicado em } \\
\text { todo paciente } \\
\text { de terapia } \\
\text { intensiva? }\end{array}$ & $\begin{array}{lr}\text { Rev } & \text { Soc } \\
\text { Cardiol } & \text { Est } \\
\text { São Paulo } & \end{array}$ & 1997 & $\begin{array}{l}\text { Revisão da } \\
\text { literatura }\end{array}$ & $\begin{array}{l}\text { Knobel, } \\
\text { Akamine, } \\
\text { Fernandes } \\
\text { Junior }{ }^{7}\end{array}$ & $\begin{array}{l}\text { Identificar se o } \\
\text { CSG pode ser } \\
\text { utilizado em } \\
\text { todo tipo de } \\
\text { paciente. }\end{array}$ & $\begin{array}{l}\text { Foi abordado } \\
\text { por meio de } \\
\text { categorias o uso } \\
\text { do CSG em } \\
\text { pacientes } \\
\text { críticos e seu } \\
\text { uso em } \\
\text { pacientes } \\
\text { clínicos, } \\
\text { abordando as } \\
\text { indicações, } \\
\text { contraindicações } \\
\text { e complicações. }\end{array}$ \\
\hline 5 & $\begin{array}{l}\text { Comparison } \\
\text { between } \\
\text { replacement } \\
\text { at } 4 \text { days and } \\
7 \text { days of the } \\
\text { infection rate } \\
\text { for pulmonary } \\
\text { artery } \\
\text { catheters in an } \\
\text { intensive care } \\
\text { unit }\end{array}$ & Crit Care Med & 2003 & $\begin{array}{l}\text { Estudo } \\
\text { descritivo, } \\
\text { exploratório, } \\
\text { de } \\
\text { intervenção, } \\
\text { com análise } \\
\text { quantitativa. }\end{array}$ & $\begin{array}{ll}\text { Chen, } & \text { Yen, } \\
\text { Yang, } & \text { Liu, } \\
\text { Wang, } & \\
\text { Chou }^{8} & \end{array}$ & \begin{tabular}{|lll} 
& \\
& \\
& \\
& \\
& & \\
& & \\
& & \\
Comparar & a \\
relação & entre & o \\
tempo & de \\
pulmonar & \\
substituição & de \\
cateter & de \\
artéria (quatro \\
dias our sete \\
dias & depois \\
inserção) e & a \\
ocorrência & de \\
infecções & \\
associadas & ao \\
uso de cateter.
\end{tabular} & 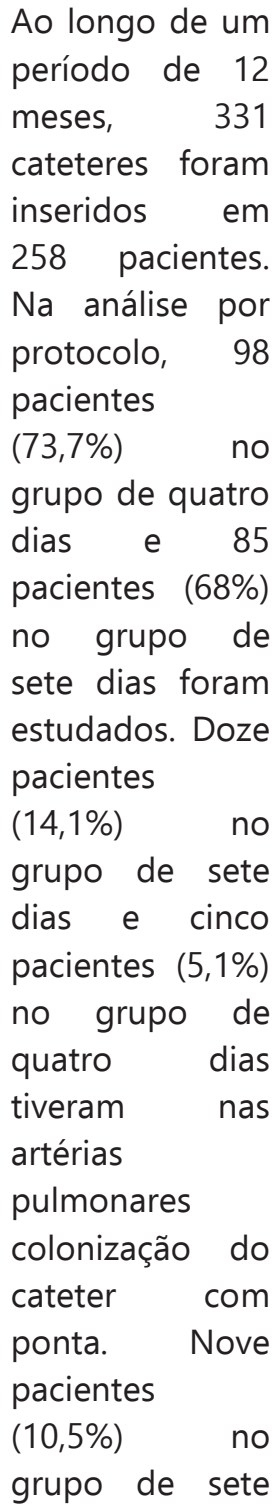 \\
\hline
\end{tabular}




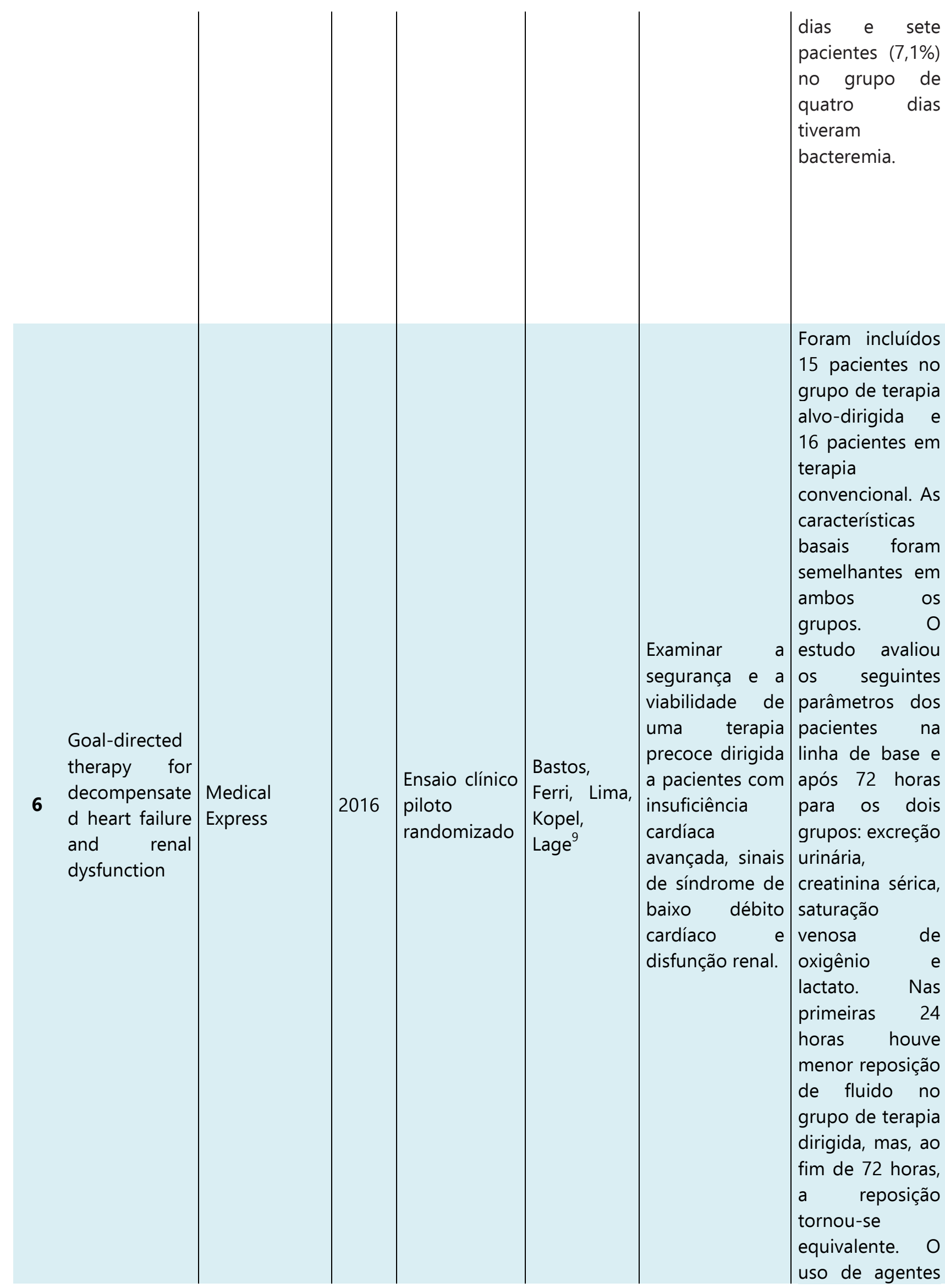




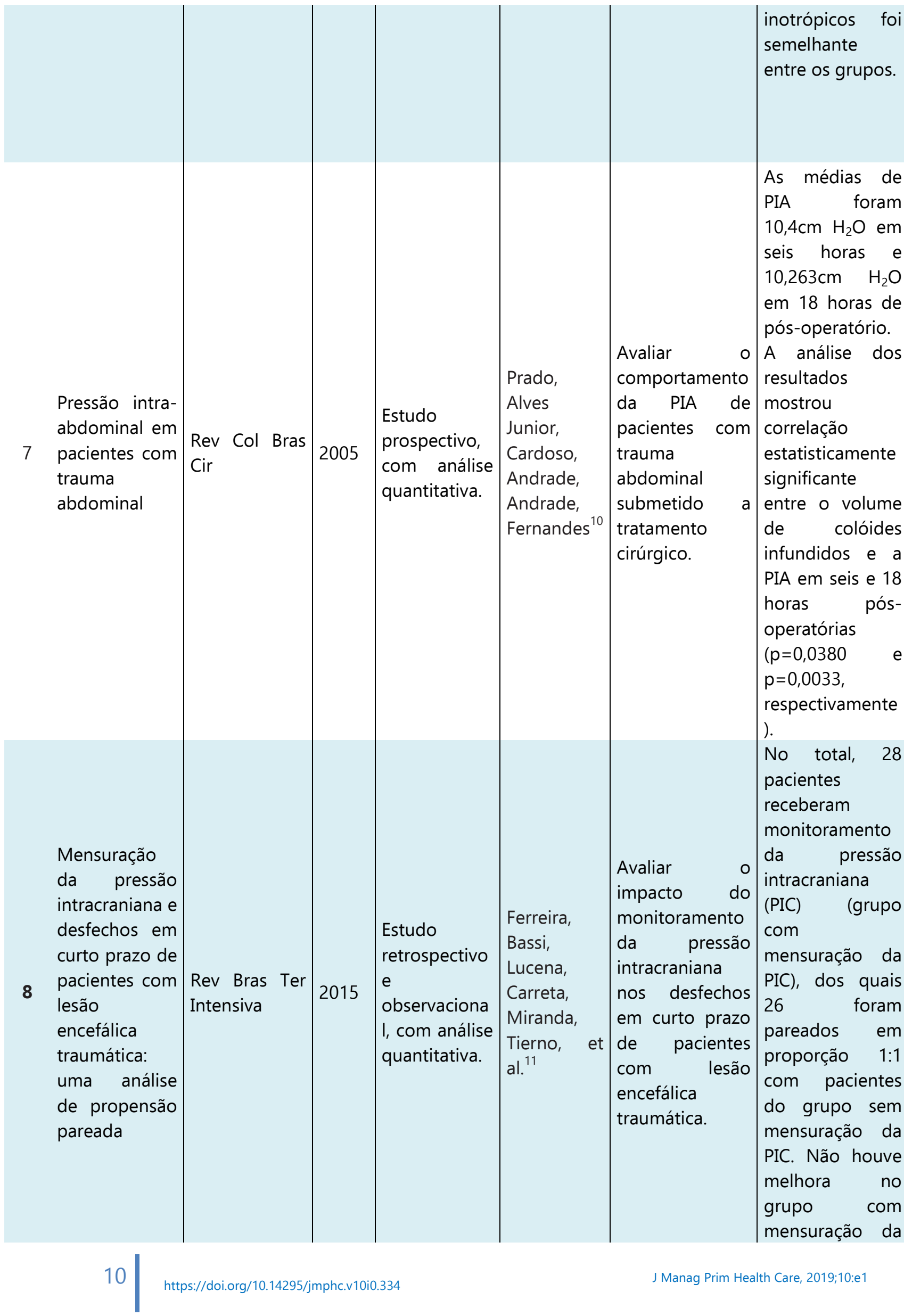




\begin{tabular}{|c|c|c|c|c|c|c|c|}
\hline & & & & & & & $\begin{array}{l}\text { PIC em } \\
\text { comparação } \\
\text { àquele sem } \\
\text { mensuração da } \\
\text { PIC quanto à } \\
\text { mortalidade } \\
\text { hospitalar, à } \\
\text { mortalidade aos } \\
14 \text { dias, ou à } \\
\text { mortalidade } \\
\text { combinada } \\
\text { hospitalar e em } \\
\text { hospital de } \\
\text { retaguarda. A } \\
\text { sobrevivência } \\
\text { até } 14 \text { dias foi } \\
\text { também similar } \\
\text { entre os grupos. }\end{array}$ \\
\hline 9 & $\begin{array}{l}\text { Avaliação da } \\
\text { variabilidade } \\
\text { de } \\
\text { intervenções } \\
\text { baseadas no } \\
\text { cateter de } \\
\text { artéria } \\
\text { pulmonar. } \\
\text { Experiência } \\
\text { brasileira }\end{array}$ & $\begin{array}{l}\text { Rev Bras Ter } \\
\text { Intensiva }\end{array}$ & 2006 & $\begin{array}{l}\text { Estudo } \\
\text { exploratório, } \\
\text { com análise } \\
\text { quantitativa. }\end{array}$ & $\begin{array}{l}\text { Mendes, } \\
\text { Rezende, } \\
\text { Dias, Réa- } \\
\text { Neto }^{12}\end{array}$ & 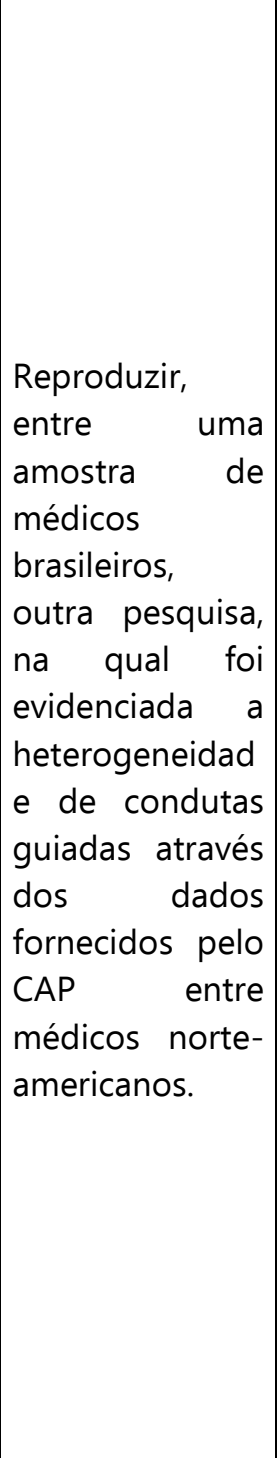 & $\begin{array}{l}\text { Duzentos e } \\
\text { trinta e sete } \\
\text { médicos } \\
\text { responderam os } \\
\text { formulários. Em } \\
\text { todos os três } \\
\text { casos foram } \\
\text { observados } \\
\text { escolhas de } \\
\text { intervenção } \\
\text { terapêutica } \\
\text { completamente } \\
\text { distinta, } \\
\text { nenhuma delas } \\
\text { obtendo mais de } \\
\text { 80\% de } \\
\text { concordância. } \\
\text { Quando se } \\
\text { comparam as } \\
\text { escolhas } \\
\text { direcionadas } \\
\text { pelos resultados } \\
\text { da } \\
\text { ecocardiografia, } \\
\text { observou-se a } \\
\text { persistência da } \\
\text { variação de de } \\
\text { escolhas e que } \\
\text { nenhuma delas } \\
\text { alcançou } \\
\text { número }\end{array}$ \\
\hline
\end{tabular}




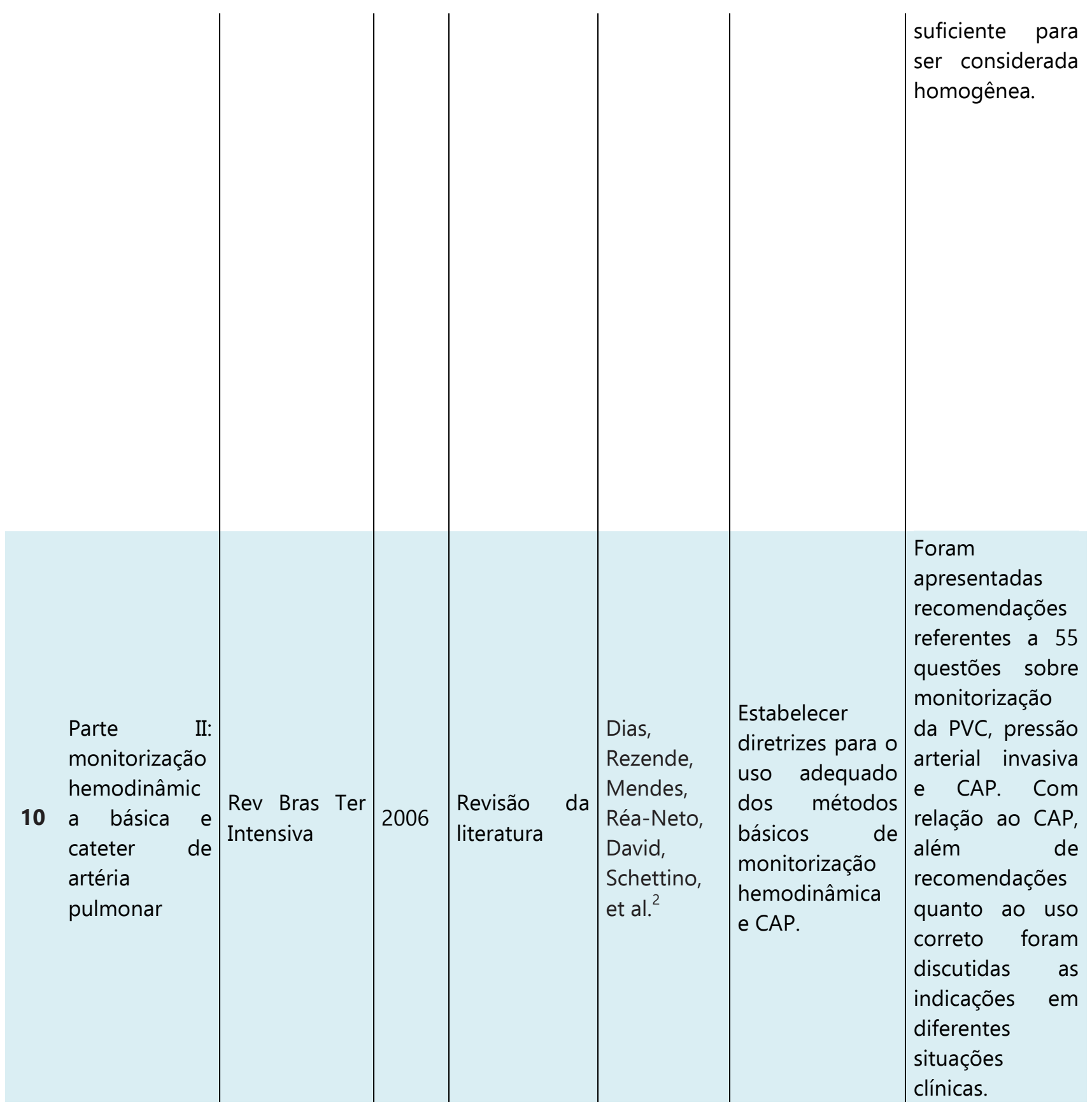




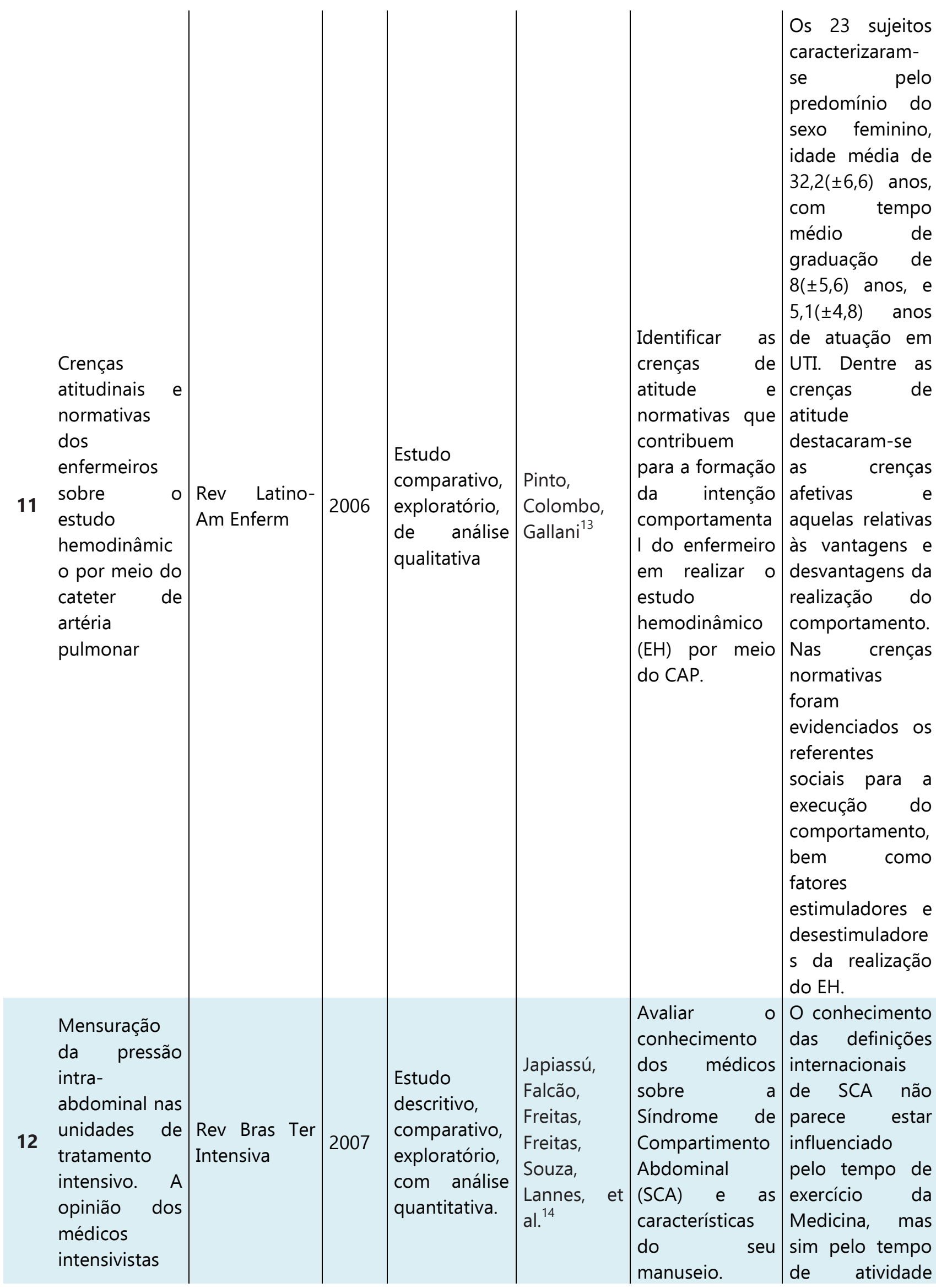




\begin{tabular}{|c|c|c|c|c|c|c|c|}
\hline & & & & & & & $\begin{array}{lr}\text { dedicada } & \text { à } \\
\text { Medicina } & \\
\text { Intensiva. } & \\
\text { Embora } & \text { a } \\
\text { maioria } & \text { esteja } \\
\text { ciente } & \text { da } \\
\text { existência } & \text { da } \\
\text { SCA, menos } & \text { da } \\
\text { metade } & \text { dos } \\
\text { médicos } & \text { que } \\
\text { responderam } & \text { ao } \\
\text { questionário } & \\
\text { conhece } & \text { as } \\
\text { definições } & \\
\text { internacionais } \\
\text { de 2004. }\end{array}$ \\
\hline 13 & $\begin{array}{l}\text { Monitorização } \\
\text { hemodinâmic } \\
\text { a invasiva a } \\
\text { beira do leito: } \\
\text { avaliação e } \\
\text { protocolo de } \\
\text { cuidados de } \\
\text { enfermagem }\end{array}$ & $\begin{array}{l}\text { Rev Esc } \\
\text { Enferm USP }\end{array}$ & 2008 & $\begin{array}{l}\text { Pesquisa- } \\
\text { ação com } \\
\text { abordagem } \\
\text { qualitativa e } \\
\text { quantitativa. }\end{array}$ & $\begin{array}{l}\text { Ramos, Dal } \\
\text { Sasso, } \\
\text { Martins, } \\
\text { Nascimento } \\
\text { Barbosa, } \\
\text { Martins, et } \\
\text { al. }^{1}\end{array}$ & $\begin{array}{lll}\text { Estabelecer } & \text { os } \\
\text { parâmetros } & \text { de } \\
\text { avaliação clínica } \\
\text { necessários } & \text { ao } \\
\text { paciente } & \\
\text { submetido } & \text { à } \\
\text { monitorização } & \\
\text { hemodinâmica } \\
\text { pelo } & \text { CAP } & \text { e } \\
\text { construir } & \text { um } \\
\text { Protocolo } & \text { de } \\
\text { Cuidados } & \text { de } \\
\text { Enfermagem } & \text { ao } \\
\text { paciente grave. }\end{array}$ & $\begin{array}{l}\text { Os critérios de } \\
\text { avaliação clínica } \\
\text { necessários ao } \\
\text { paciente } \\
\text { submetido à } \\
\text { monitorização } \\
\text { hemodinâmica } \\
\text { se constituem } \\
\text { em parâmetros } \\
\text { invasivos e não } \\
\text { invasivos e que } \\
\text { o protocolo } \\
\text { fundamenta a } \\
\text { tomada de } \\
\text { decisão clínica } \\
\text { para o cuidado } \\
\text { do paciente em } \\
\text { uso do CAP. }\end{array}$ \\
\hline 14 & $\begin{array}{l}\text { Síndrome } \\
\text { compartiment } \\
\text { al abdominal }\end{array}$ & $\begin{array}{l}\text { Soc Bras Clin } \\
\text { Med }\end{array}$ & 2009 & $\begin{array}{l}\text { Revisão da } \\
\text { literatura }\end{array}$ & $\begin{array}{l}\text { Bersani, } \\
\text { Gomes, } \\
\text { Braga, } \\
\text { Guimarães, } \\
\text { Lopes }^{15}\end{array}$ & \begin{tabular}{|lr} 
Fornecer & \\
atualização & \\
clínica para & um \\
diagnóstico & \\
preciso, & \\
manuseio & e \\
intervenção & \\
adequados & na \\
SCA, & com \\
particular & \\
ênfase & em \\
cuidados & \\
intensivos. &
\end{tabular} & 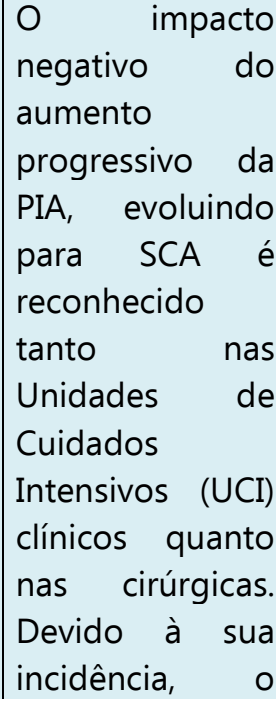 \\
\hline
\end{tabular}


ISSN 2179-6750

\begin{tabular}{|c|c|c|c|c|c|c|c|}
\hline & & & & & & & \begin{tabular}{lr}
\multicolumn{3}{l}{ manejo diário da } \\
PIA deve ser \\
rotina & nos \\
pacientes & de \\
alto risco, na \\
UTI.
\end{tabular} \\
\hline 15 & $\begin{array}{l}\text { Complicações } \\
\text { da } \\
\text { monitorização } \\
\text { da pressão } \\
\text { intracraniana } \\
\text { intra- } \\
\text { parenquimato } \\
\text { sa: revisão de } \\
\text { literatura }\end{array}$ & Rev Med Res & 2011 & $\begin{array}{l}\text { Revisão da } \\
\text { literatura }\end{array}$ & $\begin{array}{l}\text { Kochi, } \\
\text { Manetti, } \\
\text { Freitas, } \\
\text { Kristochick, } \\
\text { Beleze, } \\
\text { Maeda, et } \\
\text { al. }\end{array}$ & $\begin{array}{l}\text { Identificar as } \\
\text { principais } \\
\text { complicações } \\
\text { do } \\
\text { monitoramento } \\
\text { da PIC. }\end{array}$ & 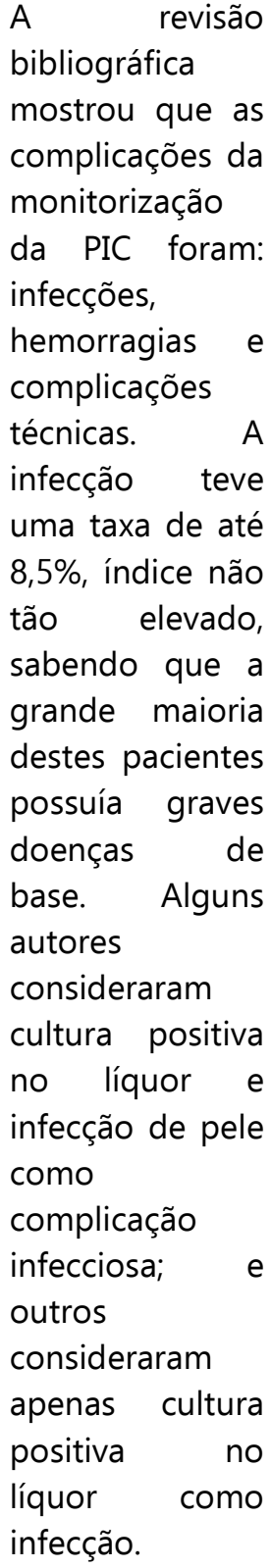 \\
\hline
\end{tabular}


Condutas no

paciente com Rev Bras Clin

trauma crânio

encefálico

\section{Med}

17

A importância do controle de pressão

Intracraniana em pacientes neurocríticos
2011

Revisão

Gentile, Himuto HS, literatura

da Rojas,

Veiga,

Amaya,

Carvalho ${ }^{17}$

Amaya,
Carvalho $^{17}$

Uningá Rev

\section{Definir}

atualizar

protocolos atendimento a

vítimas de trauma crânioencefálico (TCE) na emergência médica, visando o diagnóstico e tratamento precoce.

\section{Investigar a} importância da medida da PIC entre pacientes internados em UTI.
O TCE é uma situação comum no cotidiano médico, sendo responsável por altas taxas de mortalidade e morbidade em todo o mundo. Apresenta-se de formas variadas, que devem ser reconhecidas precocemente pelo médico ainda no atendimento primário com o exame clínico e neurológico, assim como deve ser precoce o início dos procedimentos avançados de suporte à vida $\mathrm{e}$ condutas específicas que tem como objetivo diminuir a incidência de lesões neuronais secundárias ao trauma.

Com a monitorização da PIC é possível detectar precocemente alterações intracranianas e evitar complicações decorrentes da hipertensão intracraniana (HIC) com o estabelecimento 


\begin{tabular}{|c|c|c|c|c|c|c|c|}
\hline & & & & & & & $\begin{array}{l}\text { de intervenções } \\
\text { terapêuticas que } \\
\text { visam à } \\
\text { otimização do } \\
\text { fluxo sanguíneo } \\
\text { cerebral (FSC). }\end{array}$ \\
\hline 18 & $\begin{array}{l}\text { Monitorização } \\
\text { hemodinâmic } \\
\text { a no paciente } \\
\text { crítico }\end{array}$ & Rev HUPE & 2013 & $\begin{array}{l}\text { Revisão da } \\
\text { literatura }\end{array}$ & Silva ${ }^{19}$ & $\begin{array}{l}\text { Descrever a } \\
\text { prática de } \\
\text { monitorização } \\
\text { hemodinâmica } \\
\text { no paciente } \\
\text { crítico. }\end{array}$ & $\begin{array}{l}\text { A prática de } \\
\text { monitorização } \\
\text { hemodinâmica } \\
\text { associada a } \\
\text { variáveis } \\
\text { dinâmicas } \\
\text { permite predizer } \\
\text { quais pacientes } \\
\text { possivelmente } \\
\text { se beneficiará de } \\
\text { terapia de } \\
\text { expansão de } \\
\text { volume } \\
\text { intravascular, um } \\
\text { dado } \\
\text { extremamente } \\
\text { relevante no } \\
\text { manuseio do } \\
\text { paciente } \\
\text { hipotenso na } \\
\text { UTI. }\end{array}$ \\
\hline
\end{tabular}

\section{Discussão}

A HIC é identificada como a principal complicação de várias enfermidades neurológicas, conhecida há mais de 200 anos. Desde o século XVIII, através da realização de autópsias, os tumores da região cerebral foram apontados como causadores de HIC. A partir do início do século XX, os livros de neurologia já descreviam sintomas como cefaleia, vômitos e a presença de papiledema nos pacientes que apresentavam aumento da PIC. O início da monitorização da PIC para avaliação clínica em doenças foi realizada por Lundberg em $1960{ }^{16}$

Foi nos EUA que ocorreu a primeira aplicação da mensuração da PIC no TCE, como forma de complementar a avaliação em pacientes graves submetidos a cirurgias neurológicas. Logo, se pode descrever a PIC como a relação física entre o conteúdo 
intracraniano e o crânio em relação à pressão atmosférica. Esta pressão reflete a variação do FSC, o qual flutua ritmicamente com os ciclos cardíacos e respiratórios. Essa pressão se apresenta em formas de onda e possui duas fases distintas, que são: a primeira fase é a transmissão direta das contrações do ventrículo esquerdo do coração. Esse pico inicial de rápida ascensão é seguido por um descenso com o início na diástole. Logo depois há uma segunda fase, que corresponde à contração elástica das artérias de grosso calibre, havendo então o retorno à linha de base. Num adulto, o crânio comporta um volume total de 1450mL: $1300 \mathrm{~mL}$ de tecido cerebral, $65 \mathrm{~mL}$ de líquido cefalorraquidiano e $100 \mathrm{~mL}$ de sangue. A hipótese de Monroe-Kellie afirma que em um estado não patológico, o volume de sangue, cérebro, líquor, e demais componentes são constantes. ${ }^{16}$

Um aumento de volume de qualquer um deles deverá repercutir na diminuição de outro elemento, ou então a pressão total do sistema irá se elevar. HIC, portanto, é definida como a elevação da pressão acima de $20-25 \mathrm{mmHg}$. A variação normal da PIC muda de acordo com a idade. Valores normais para adultos, adolescentes e pré-adolescentes estão entre $10-15 \mathrm{mmHg} ; 3-7 \mathrm{mmHg}$ para criança, e $1,5-6 \mathrm{mmHg}$ para lactentes. Porém, seus valores pediátricos ainda não são absolutos. As causas mais comuns relacionadas ao aumento da PIC são classificadas em causas pós-operatórias, extra e intracranianas. Tumor cerebral, trauma (hematomas subdurais, extradurais e concussões cerebrais), hemorragias não traumáticas, acidente vascular cerebral (AVC) isquêmico, hidrocefalia, hipertensão idiopática são considerados causas intracranianas. Causas extracranianas são as obstruções de vias aéreas, hipóxia ou hipercarbia, hipertensão ou hipotensão, postura, hipertermia, convulsões, drogas e alterações metabólicas diversas. Causas pós-operatórias são hematomas, edema, vasodilatação. ${ }^{11}$

Existem várias indicações para a monitorização da PIC, dentre elas se destacam o TCE moderado e grave, hidrocefalia, pós-operatório neurocirúrgico, onde exista risco de evolução de lesões, com efeito, massa como as hemorragias, e encefalopatias metabólicas. A aferição é feita a partir da introdução invasiva de um sensor, ligado a um monitor 
pressórico, em um dos quatro sítios de localização cerebral: epidural, subdural, intraventricular e intraparenquimatoso. ${ }^{16}$ Ao considerar que as lesões cerebrais secundárias ao trauma causam alterações sistêmicas e intracranianas, podendo ocorrer a qualquer momento durante a fase de reanimação e estabilização, também durante o tratamento em UTI, é preciso que a equipe multiprofissional - o que inclui a enfermagem - esteja preparada para a adoção de condutas e realização de procedimentos cujo alvo é otimizar a perfusão cerebral, a oxigenação tecidual, prevenindo agravos maiores. ${ }^{17}$

Nesse contexto, o enfermeiro que assiste diretamente ao paciente neurocrítico internado em UTI, tem um papel importante na detecção precoce de alterações da PIC para que, junto aos demais profissionais intensivistas, sejam adotadas condutas intervencionistas capazes de viabilizar a estabilização e recuperação do doente neurocrítico. ${ }^{18}$ Quanto aos cuidados de enfermagem que se deve ter com relação ao paciente, tem-se: manter decúbito de 15 a 30 (ou conforme orientação da neurocirurgia); zerar o cateter de Derivação Ventricular Externa - DVE no conduto auditivo externo; fechar o cateter de DVE durante o transporte do paciente e abri-lo em seguida; desprezar a bolsa coletora quando atingir 2/3 de sua capacidade, ao manipular a via de saída da bolsa, manter técnica asséptica; realizar curativo na região peri-cateter observando se há extravazamento de líquor ou sinais flogísticos; anotar débito, aspecto e cor da drenagem de líquor. ${ }^{2}$

A PVC é a medida da pressão sanguínea nas grandes veias de retorno ao átrio direito ou a pressão de enchimento do ventrículo direito. Representa a medida da capacidade relativa do coração em bombear o sangue venoso. Deve-se mencionar que o ponto zero da coluna de fluido deve ficar situado no mesmo nível que o átrio direito, sendo a diferença de altura do menisco de fluido, em relação ao ponto zero, a leitura da PVC, no que concorda como ponto de referência para a localização do átrio direito, a linha média do esterno, quando o paciente se encontra em decúbito lateral. A PVC é a pressão de retorno do sangue ao lado direito do coração e é um importante parâmetro a ser 
aferido em numerosas situações clínicas, cirúrgicas e experimentais. Para sua realização, utiliza-se um CVC aplicado preferencialmente na veia jugular. ${ }^{9}$

A medida da PVC é um dos primeiros passos na avaliação da volemia e da função cardíaca de pacientes graves. A PVC pode contribuir para avaliação e controle do estado do volume intravascular. Como tal análise relaciona retorno venoso com função ventricular, variações na complacência de um dos ventrículos ou na capacitância venosa podem provocar erros nesta correlação, como ocorre na disfunção diastólica, na ventilação mecânica e com o uso de drogas vasoativas. A avaliação da PVC como indicador de volemia deve ser realizada através da resposta à infusão de líquidos, de modo seriado. A ausência de aumentos na PVC de até $3 \mathrm{mmHg}$, após prova de volume padronizada, quase sempre é garantia de bom desempenho cardíaco e de espaço para reposição volêmica. Apesar das limitações como método de avaliação da volemia, é o mais simples, pouco invasivo e disponível rapidamente à beira do leito. A variação de $2-3 \mathrm{mmHg}$ durante a inspiração sugere que este grupo de pacientes tem maior probabilidade de aumentar o índice cardíaco (IC) em resposta à infusão de líquidos. Além disso, a PVC pode ser utilizada como um dos parâmetros de otimização hemodinâmica, como em pacientes sépticos graves. $^{2}$

A PVC deve ser utilizada em todo paciente no qual haja dúvida quanto ao estado volêmico e cuja correção interfira na evolução clínica, principalmente nos estágios iniciais das seguintes condições: choque de qualquer etiologia; desconforto respiratório grave; insuficiência renal aguda (IRA); sepse grave; e acidente com alto risco cirúrgico e submetido à cirurgia de grande porte, passagem de marcapasso, infusão de drogas, coleta de sangue, entre outros. Não há contraindicação à monitorização da PVC, mas sim ao acesso vascular central. As contraindicações são ao acesso vascular central em pacientes com síndromes obstrutivas da veia cava superior, trombose venosa profunda (TVP) de membros superiores (MMSS), infecção ou queimadura nos locais de acesso, bem como 
limitações anatômicas. Entretanto, o acesso venoso central, na maioria dos pacientes graves, é factível e realizado sem dificuldades. ${ }^{2}$

A medida da PVC através de manômetro ou coluna líquida é menos precisa do que a medida eletrônica contínua com a utilização de transdutores de pressão. Esta apresenta melhor correlação com a medida através do registro do traçado de PV, considerado "padrão ouro". Quando a monitorização digital contínua não for possível, a precisão de medidas manométricas parece melhor quando são utilizadas as veias jugulares internas ou a subclávia esquerda. ${ }^{2}$ Os cuidados que se deve ter para com a verificação da PVC são as seguintes: manter o paciente em posição supina, sem o travesseiro; certificar-se do correto posicionamento do transdutor; identificar o zero hidrostático; verificar o comprimento do circuito (até $110 \mathrm{~cm}$ ); verificar o preenchimento completo do cateter com líquido (remover bolhas e coágulos); realizar o Teste de "lavagem" ("Flush Test"); "zerar" o sistema em relação à pressão atmosférica; verificar o posicionamento da ponta do CVC; identificar as ondas de PVC; realizar a medida no final da expiração, tanto em pacientes intubados como em ventilação espontânea; e verificar a morfologia da curva (afastar sub ou superamortecimento) e sua relação com o ciclo respiratório.

Os CVC são indispensáveis na prática médica moderna, principalmente em UTI, onde o seu uso tem sido crescente. Esses dispositivos são utilizados principalmente em pacientes idosos, portadores de co-morbidades, com hospitalização prolongada e em uso de antibióticos de largo espectro. Tais fatores aumentam a incidência e gravidade de complicações mecânicas e infecciosas relacionadas ao uso dos CVC. A melhoria, tanto na habilidade dos médicos durante o procedimento de inserção dos cateteres quanto dos cuidados de enfermagem durante a sua permanência, tem contribuído para reduzir as taxas de complicações associadas ao uso de tais dispositivos. ${ }^{2}$ As vias preferências de CVC para monitorização da PVC, em ordem de preferência, são: jugular direita; jugular esquerda; subclávia esquerda; subclávia direita; femoral direita ou esquerda; e cateter central de inserção periférica (PICC). 
O CAP ou CSG foi introduzido nas práticas de monitorização invasiva em 1970 e difundiu-se de maneira rápida devido a sua praticidade e eficácia. É considerado instrumento de grande importância na medida das pressões hemodinâmicas e na determinação do débito cardíaco (DC), e funciona como guia na administração de líquidos intravenosos, inotrópicos e agentes redutores da pós-carga. ${ }^{13}$ Entre os parâmetros de monitorização dados pela CAP estão às medidas de pressão do átrio direito (PAD), pressão da artéria pulmonar (PAP) sistólica e diastólica, DC, IC e PV pulmonar, também chamada de pressão de oclusão da artéria pulmonar (POAP). A POAP e obtida com a insuflação do balonete distal do cateter e permite predizer, em condições ideais, a PV do átrio esquerdo e a pressão diastólica final do ventrículo esquerdo, um dado da pré-carga do ventrículo. Tais parâmetros permitem determinar um diagnóstico, guiar e melhorar o tratamento do paciente, e devem ser coletados com uma frequência de pelo menos 4-6 horas por médicos ou enfermeiros. ${ }^{2,13,1,19}$

O valor do DC é obtido pelo método de termodiluição, baseada nos princípios de Stewart-Hamilton, em que um líquido de temperatura diferente do sangue e injetado na via proximal do cateter e um termistor localizado na ponta do cateter detectam a diferença de temperatura do sangue e calcula o débito de forma intermitente. Outro dado que pode ser obtido é a saturação venosa mista de $\mathrm{O} 2\left(\mathrm{Sat}_{\mathrm{ven}} \mathrm{O}_{2}\right)$ através da via distal do cateter, que através desse dado, pode-se obter a $\mathrm{DO}_{2}$ (oferta de oxigênio), $\mathrm{VO}_{2}$ (consumo de oxigênio) e percentual de shunt pulmonar. Essas informações e as informações das medidas pressóricas podem ser obtidas simultaneamente, o que se trata de uma vantagem sobre os demais tipos de monitorização. ${ }^{19}$

O CAP é indicado nas patologias que necessitam de informações sobre a pré-carga, a pós-carga, contratilidade, consumo e oferta de oxigênio. Portanto, é utilizado nos casos de choque cardiogênico, infarto agudo do miocárdio (IAM), insuficiência cardíaca congestiva refratária (ICCR), período perioperatório em pacientes graves, choque séptico e Síndrome do Desconforto Respiratório Agudo - SDRA. É contraindicado para pacientes em 
fase terminal ou com determinação de limite para o suporte terapêutico (comprometimento neurológicos extensos, neoplasias disseminadas e outras doenças graves com mau prognóstico), com risco inaceitável para acesso venoso e na presença de hipotermia, pois há risco aumentado de disritmias cardíacas. ${ }^{1,2,7}$

A sua colocação deve ser feita por médicos experientes com a técnica de inserção para viabilizar o procedimento com segurança e com nível de conhecimento avançado para a correta averiguação e interpretação dos dados obtidos, pois podem ocorrer complicações como arritmia cardíaca, em sua maioria transitória e sem risco para o paciente, ou de complicações associadas à punção venosa, como infecção relacionada ao cateter e ruptura da artéria pulmonar." ${ }^{5,2.20}$ Além dessas complicações pode ocorrer hemorragia, formação de hematomas e embolização de placas ateroscleróticas. As arritmias podem ocorrer na inserção e remoção ou durante a passagem do balão pelo ventrículo direito, este tipo de complicação pode ser minimizado pela velocidade com que se atravessa o ventrículo direito com o balão insuflado. A manutenção do cateter em posição na artéria pulmonar pode levar a infartos pulmonares, que podem ser prevenidos através do posicionamento proximal do cateter pela infusão contínua de solução heparinizada, e com o cuidado em não se manter o balão insuflado além do necessário. ${ }^{7}$

Dependendo da necessidade de orientação diagnóstica e terapêutica, deve-se restringir o uso do CAP ao menor tempo possível (menos de 96 horas). Após este período, é recomendável reinserir outro cateter, se a monitorização hemodinâmica com o CAP ainda for necessária, pois as complicações aumentam substancialmente. Porém, a cateterização além de 72 horas e manipulações múltiplas aumentam a chance de colonização e a taxa de infecção relacionada ao cateter. ${ }^{7,6,8}$ A correta análise dos dados obtidos pelo CAP, incluindo a sua correta localização, fundamenta o diagnóstico e a terapêutica de pacientes hemodinamicamente instáveis. E muitas vezes as decisões terapêuticas são baseadas nos dados colhidos pelos enfermeiros, portanto a interpretação 
errada ou a incapacidade de reconhecer complicações pode levar ao agravamento da condição do doente aumentando a morbimortalidade. ${ }^{21,19}$

Os cuidados que devem ser tomados na monitorização hemodinâmica com a utilização do CAP são:

Manter o paciente em posição supina, sem o travesseiro; certificar-se do correto posicionamento do transdutor em relação ao decúbito; identificar o zero hidrostático; verificar comprimento do circuito (até $110 \mathrm{~cm}$ ); examinar o preenchimento completo do cateter com líquido (remover bolhas e coágulos); realizar Teste de "Lavagem" ("Flush Test"); "zerar" com a pressão atmosférica; identificar as ondas de CAP: PAD, PVD, PAP e POAP; procurar relacionar a onda "a" do traçado pressórico com o final da onda $P$ do traçado do eletrocardiograma (ECG); realizar a medida no final da expiração, tanto em pacientes entubados como naqueles com ventilação espontânea; verificar a morfologia das curvas (para afastar sub e superamortecimento) e suas relações com o ciclo respiratório; verificar o posicionamento da ponta do cateter através de radiografia de tórax. ${ }^{2: 71-2}$

As atividades desenvolvidas pela enfermagem consistem na prestação de cuidados e na execução de procedimentos diagnósticos e terapêuticos. Ressaltando a utilização da CAP, os cuidados de enfermagem mais evidenciados são: observação constante das alterações do estado clínico do doente, avaliação da eficácia dos tratamentos aplicados, avaliação do local de inserção dos cateteres, realização de curativo com cuidados de assepsia rigorosa, vigiar as complicações e posicionar o doente em decúbito dorsal com os transdutores corretamente posicionados para evitar erros de leitura. ${ }^{21,1}$

A cavidade abdominal é um compartimento com complacência limitada. Vítimas de trauma abdominal grave, principalmente os submetidos à laparotomia frequentemente apresentam aumento da PIA. Os efeitos adversos da hipertensão intra-abdominal (HIA) são conhecidos há muitos anos, mas apenas recentemente deu-se importância clínica a PIA elevada. ${ }^{14}$ A PIA pode ser medida através de cateter vesical de Foley acoplado a um manômetro de água. Seus valores normais variam entre $0-12 \mathrm{mmHg}$ e podem estar relacionados ao índice de massa corporal (IMC) de acordo com alguns autores. Pressões acima de 15-20mmHg são capazes de causar redução do débito urinário, aumento da pressão respiratória e redução do DC. Quando maiores que $25 \mathrm{mmHg}$, mudanças 
fisiológicas são frequentes e clinicamente significativas: muitos médicos consideram este nível de PIA suficiente para indicar descompressão cirúrgica. ${ }^{10,14}$ Em grande parte dos casos é medida na suspeita clínica de HIA. Recentemente, a PIA tem sido utilizada conjuntamente com medidas respiratórias para ajuste da ventilação mecânica. ${ }^{14}$ Indica-se mensurar a PIA em caso de trauma abdominal; distensão abdominal; dificuldade respiratória; hipercapnia; oligúria; redução do DC; e hipóxia.

A PIA deve ser interpretada em $\mathrm{mmHg}$, medida no final da expiração e com o paciente na posição supina, na ausência de contração abdominal. O transdutor deve estar posicionado com o zero na linha axilar média. A medida vesical é o método considerado mais simples e com menor custo. Um conector de três vias é inserido entre a sonda vesical e o coletor, que é conectado a um transdutor de pressão e permite medir a pressão intravesical após instilação de solução salina na bexiga. Como o método é intermitente, deve ser realizado no intervalo de 4 a 6 horas, exceto nos pacientes com disfunção orgânica grave, os quais devem ter sua medida de hora em hora. A medida da PIA pode ser descontinuada se o paciente não tiver mais disfunção orgânica aguda e valores de PIA $<10 \mathrm{mmHg}$ por $24-48 \mathrm{~h}^{15}$

A PIA normal varia de $0-12 \mathrm{mmHg}$ em adultos. Algumas condições fisiológicas como obesidade mórbida, tumor ovariano, cirrose ou gravidez possivelmente estão associadas à elevação crônica da PIA de 10-15 mmHg sem significado fisiopatológico. O contrário é visto nas crianças que geralmente possuem valores baixos de PIA. ${ }^{15} \mathrm{~A}$ PIA varia com a respiração. A mensuração da PIA pode ser feita de forma direta ou indireta. Deve sempre ser medida em mmHg e com o paciente em posição supina ao final da expiração. ${ }^{10} \mathrm{O}$ método direto é realizado pela introdução de um cateter ou agulha na cavidade peritoneal, conectado a um equipo e um manômetro de pressão. Já o método indireto é mais utilizado e é realizado através da pressão intravesical, com o paciente em uso de sonda vesical de demora. 
O Conselho Regional de Enfermagem de São Paulo - COREN-SP 22 define etapas a ser seguida para a mensuração da PIA, sendo elas: (a) colocar o paciente em posição supina; (b) realizar a sondagem vesical do paciente, com sonda Foley de duas ou três vias, mantendo-a aberta para a drenagem do conteúdo vesical em sistema fechado; (c) calce luvas estéreis e realize a anti-sepsia da via de aspiração, com solução alcoólica 70\%; (d) utilize o sistema de mensuração adequado e de acordo com o protocolo institucional; (e) clampeie a bolsa de drenagem do débito urinário, imediatamente abaixo da via de aspiração (ponto de coleta) do sistema; (f) calibre o transdutor de pressão; $(g)$ infunda $1 \mathrm{~mL} / \mathrm{kg}$ para crianças de até sete anos de idade, e para crianças maiores e adultos até o máximo de $25 \mathrm{mLde}$ solução salina na bexiga, ou de acordo com o protocolo institucional; (h) realize a leitura da PIA no final da expiração, no monitor de pressão ou na coluna de solução salina após a estabilização, o valor é registrado com base na altura da coluna em relação ao ponto zero; (i) desclampei a via de drenagem da bolsa; (j) desconte o volume infundido do débito urinário a cada mensuração da PIA; (I) documente a realização do procedimento e os valores pressóricos no impresso de controles, avaliando a evolução clínica e os resultados dos cuidados de enfermagem; (m) repita o procedimento a cada oito horas ou quando necessário.

A equipe de enfermagem deve observar e seguir os seguintes cuidados: manter sempre o saco coletor abaixo da cama do paciente; não desconectar o sistema na junção entre a sonda e o conector da bolsa coletora. Caso isso ocorra, deve-se retirar a sonda e realizar nova sondagem vesical; se houver necessidade de trocar a bolsa coletora (quebra da pinça, inutilidade do dispositivo) deve-se realizar nova sondagem vesical; ao desprezar a quantidade de urina da bolsa coletora, deve-se utilizar um recipiente único para cada paciente; deve-se fixar a sonda corretamente; ao transferir o paciente do leito, lembrar sempre de pinçar o tubo do saco coletor para que não haja refluxo da urina da bolsa coletora para dentro da bexiga. 


\section{Conclusão}

O conhecimento acerca da monitorização hemodinâmica invasiva ajuda a desenvolver a capacidade de decisão clínica, passando do simples registro dos sinais vitais para a interpretação e análise daquela informação, de modo a formular um plano de cuidados de enfermagem apropriado para aquele indivíduo.

Por meio deste, é possível inferir que, de todos os artigos da amostra analisados, constatou-se que o número de pacientes graves em estado crítico tem aumentado consideravelmente por múltiplas causas de modo que, tanto a demanda nas UTI, quanto o uso da monitorização hemodinâmica invasiva neste setor, tem se tornado de fundamental importância para o tratamento e recuperação do paciente.

É importante salientar a necessidade de preparar melhor os profissionais de saúde para o cuidado dos pacientes com esses dispositivos no sentido de desenvolver um cuidado mais associativo e baseado na evidência.

\section{Referências}

1. Ramos CCS, Dal Sasso GTM, Martins CR, Nascimento ER, Barbosa SFF, Martins JJ, et al. Monitorização hemodinâmica invasiva a beira do leito: avaliação e protocolo de cuidados de enfermagem. Rev Esc Enferm USP. 2008;42(3):512-8. http://dx.doi.org/10.1590/S0080-62342008000300014.

2. Dias FS, Rezende E, Mendes CL, Réa-Neto A, David CM, Schettino G, et al. Parte II: monitorização hemodinâmica básica e cateter de artéria pulmonar. Rev Bras Ter Intensiva. 2006;18(1):63-77. http://dx.doi.org/10.1590/S0103-507X2006000100012.

3. Azevedo TRM, Oliveira LMN. Monitorização hemodinâmica invasiva. São Paulo: Abril; 2013.

4. Kron IL, Harman PK, Nolan SP. The measurement of intra-abdominal pressure as a criterion for abdominal re-exploration. Ann Surg. 1984;199(1):28-30.

5. Iberti TJ, Fischer EP, Leibowitz AB, Panacek EA, Silverstein $\mathrm{JH}$, Albertson TE. A multicenter study of physicians' knowledge of the pulmonary artery catheter. Pulmonary Artery Catheter Study Group. JAMA. 1990 Dec 12;264(22):2928-32. 
http://dx.doi.org/10.1001/jama.1990.03450220094030

6. Lima MV, Ochiai ME, Vieira KN, Cardoso JN, Brancalhão EC, Puig R, et al. Uso da monitorização hemodinâmica contínua não invasiva na insuficiência cardíaca descompensada. ArqBrasCardiol. 2012;99(3):843-47. http://dx.doi.org/10.1590/S0066$782 \times 2012005000070$

7. Knobel E, Akamine N, Fernandes Júnior CJ. O cateter de Swan-Ganz deve ser indicado em todo paciente de terapia intensiva? Rev Soc Cardiol Est São Paulo. 1997;7(2):1-21.

8. Chen YY, Yen DHT, Yang YG, Liu CY, Wang FD, Chou P. Comparison between replacement at 4 days and 7 days of the infection rate for pulmonary artery catheters in an intensive care unit. Crit Care Med. 2003;31(5):1353-8. http://dx.doi.org/10.1097/01.CCM.0000059433.79220.2B.

9. Bastos JF, Ferri M, Lima JJG, Kopel L, Lage SG. Goal-directed therapy for decompensated heart failure and renal dysfunction. A pilot randomized clinical trial. Medical Express. 2016;3(2):M160207. http://dx.doi.org/10.5935/MedicalExpress.2016.02.07.

10. Prado LFA, Alves Junior A, Cardoso ES, Andrade RS, Andrade RS, Fernandes MK. Pressão intra-abdominal em pacientes com trauma abdominal. Rev Col Bras Cir. 2005;32(2):83-9. http://dx.doi.org/10.1590/S0100-69912005000200008.

11. Ferreira CB, Bassi E, Lucena L, Carreta H, Miranda LC, Tierno PFGM, et al. Mensuração da pressão intracraniana e desfechos em curto prazo de pacientes com lesão encefálica traumática: uma análise de propensão pareada. Rev Bras Ter Intensiva. 2015;27(4):31521. http://dx.doi.org/10.5935/0103-507X.20150055.

12. Mendes $C L$, Rezende $E$, Dias FS, Réa-Neto $A$. Avaliação da variabilidade de intervenções baseadas no cateter de artéria pulmonar: experiência brasileira. Rev Bras Ter Intensiva. 2006;18(2):137-42. http://dx.doi.org/10.1590/S0103-507X2006000200006.

13. Pinto CJM, Colombo RCR, Gallani MCBJ. Crenças atitudinais e normativas dos enfermeiros sobre o estudo hemodinâmico por meio do cateter de artéria pulmonar.Rev Latino-Am Enferm. 2006;14(6):915-22. https://doi.org/10.1590/S010411692006000600013.

14. Japiassu AM, Falcão $H$, Freitas F, Freitas $S$, Souza PCP, Lannes $R$, et al. Mensuração da pressão intra-abdominal nas unidades de tratamento intensivo. A opinião dos médicos intensivistas. Rev Bras Ter Intensiva. 2007;19(2):186-91. http://dx.doi.org/10.1590/S0103507X2007000200008. 
15. Bersani AL, Gomes JO, Braga ILS, Guimarães HP, Lopes RD. Síndrome compartimental abdominal. Rev Bras Clin Med. 2009;7(1):313-21.

16. Kochi AT, Manetti HM, Freitas JF, Kristochick JCG, Beleze RJ, Maeda AK, et al. Complicações da monitorização da pressão intracraniana intraparenquimatosa: revisão de literatura. Rev Med Res. 2011;13(1):1-7.

17. Gentile JKA, Himuro HS, Rojas SSO, Veiga VC, Amaya LEC, Carvalho JC. Condutas no paciente com trauma cranioencefálico. Rev Bras Clin Med. 2011;9(1):74-82.

18. Thom GB, Inoue KC. A importância do controle de pressão intracraniana em pacientes neurocríticos [monografia]. [Maringá (PR)]: Centro Universitário Ingá; 2014.

19. Silva WO. Monitorização hemodinâmica no paciente crítico. Rev HUPE. 2013;12(3):57-65. http://dx.doi.org/10.12957/rhupe.2013.7531.

20. Mueller HS, Chatterjee K, Davis KB, Fifer MA, Franklin C, Greenberg MA, et al. Present use of bedside right heart catheterization in patients with cardiac disease. J Am Coll Cardiol. 1998;32(3):840-64. https://doi.org/10.1016/S0735-1097(98)00327-1.

21. Capitão E, Pires J. Como eu, enfermeiro, faço: monitorização hemodinâmica. Rev Port Med Int. 2009;16(3):51-5.

22. Brasil. Conselho Regional de Enfermagem de São Paulo. Mensuração de pressão intraabdominal. São Paulo: COREN-SP; 2009. 


\section{Minicurrículo}

Patrick Leonardo Nogueira da Silva | ORCiD: 0000-0003-2399-9526

Especialista em Enfermagem do Trabalho pela Faculdade de Guanambi - FG. Enfermeiro da Fundação Hospitalar do Município de Espinosa - FHUMESP. Professor da Universidade Estadual de Montes Claros UNIMONTES.

Amanda Gesiele Pereira Santos | ORCiD: 0000-0002-4946-9307

Especialista em Emergência, Trauma e Terapia Intensiva pela Universidade Estadual de Montes Claros UNIMONTES. Enfermeira do Corpo de Bombeiros Militar de Minas Gerais.

Bianca Gonçalves Rodrigues | ORCiD: 0000-0003-1822-307X

Enfermeira pela Universidade Estadual de Montes Claros - UNIMONTES.

Bruna Rodrigues Novi | ORCiD: 0000-0002-6201-9319

Enfermeira pela Universidade Estadual de Montes Claros - UNIMONTES. Servidora pública do Centro de Atenção Psicossocial - CAPS-1 de Pirapora.

Daniele Zuba Ramos | ORCIiD: 0000-0002-7695-8886

Enfermeira pela Universidade Estadual de Montes Claros - UNIMONTES.

Pollyane Teixeira Rocha | ORCID: 0000-0003-4759-2202

Enfermeira pela Universidade Estadual de Montes Claros - UNIMONTES. Servidora pública da Prefeitura Municipal de Montes Claros.

Priscila Karolline Rodrigues Cruz | ORCID: 0000-0003-0670-794X

Mestranda em Cuidado Primário em Saúde pela Universidade Estadual de Montes Claros - UNIMONTES. Servidora pública da Prefeitura Municipal de Francisco Sá.

Luciana Barbosa Pereira | ORCID: 0000-0002-0419-0353

Mestre em Ciências da Saúde pela Universidade Federal de São Paulo - UNIFESP. Professora do Departamento de Enfermagem da Universidade Estadual de Montes Claros - UNIMONTES. 